\title{
Educational strategy in digital environment
}

\author{
Irina Stikhina*
}

Ural State University of Economics, 8 Marta Street 62, 620144 Yekaterinburg, Russian Federation

\begin{abstract}
The article analyzes educational transformations as viewed by undergraduate students of the $1^{\text {st }}$ and the $4^{\text {th }}$ year as well as aspects of digital transformation based on the conducted survey. Predicated on general trends and collected data, possible development strategy of education in digital environment is introduced. It is assumed that online courses with integrated materials designed on digital platforms will command a larger part in the curricula. At the same time, as the study shows, the traditional education with face-to-face communication is still important to students. Therefore, the educational strategy should emphasize the blended format - face-to-face learning experience on campus complemented by the distance component in the form of synchronous virtual classes, enriched by asynchronous online electronic courses with e-lectures and interactive tasks for students.
\end{abstract}

\section{Introduction}

The digital landscape is one of the key aspects that is now being considered in connection with the sustainability of the learning process and teaching methods, as well as in terms of educational management.

Digital education implies, first of all, the combined use of computer technology and educational methods for teaching. At the level of the curriculum, online courses can be created (the so-called vertical integration), and the virtual landscape can be integrated into classical courses (horizontal integration) [1]. Communication and coordination are becoming more complicated when compared with traditional education. Teachers feel that they are now facilitators, mediators, intermediaries developing educational content instead of being the one who provides this content [2]. It is also argued that the widespread use of ICT tools leads to a reduction in social interaction, the curtailment of social contacts [3]. Anyway, analysis of MOOC students' ratings and reviews shows that these courses can be evaluated positively by learners. Not only high grades, persisting longer, or obtaining a certificate of accomplishment stimulate their learning process, also co-creating a positive learning experience is important to them [4].

It should also be added that specialists with creative, extraordinary thinking are required to develop educational innovations. As W. G. Faix and J. Mergenthaler state, innovations are the result of creative power, whose cause is a creative person. Again, the creative person is a result of education, among other things [5, p. 13]. Teaching, education and upbringing is carried out through communication between teachers and students, and a

\footnotetext{
* Corresponding author: aniris.irina@yandex.ru
} 
computer, as E. G. Efimova argues, is an electronic storage medium that does not have the function of upbringing and education [6]. In this regard, the designing of specialized integrated online courses with the possibility of interactive communication between teachers and students is a priority task. This task has been currently solving by different educational institutions worldwide. A lot of universities use blended learning approach, including traditional blended, blended online, and blended synchronous courses [7]. Each type supposes its own challenges. Traditional blended courses combine online with traditional on-campus learning. Blended online learning includes only online format with asynchronous and synchronous components. Blended synchronous learning approaches use media-rich synchronous technologies to enable remote and face-to-face students to coparticipate in the same live classes [8]. Such activities as class discussion, problem solving, group questioning, collaborative evaluation and design can be practicing within the digital learning process. Videoconferencing, poll applications as well as classroom chat (CC), classroom response system (CRS), e-lectures, mobile virtual reality (VR) are technologies that can be exemplarily mentioned [9]. Very essential are also digital platforms (e.g. Moodle) which enable to create integrated online courses.

The objective of this study is to consider the educational transformations as viewed by undergraduate students in terms of their expectations and preferences. The purpose is to analyze perspectives of digital transformation based on the conducted survey and to define possible development strategy. The situation with the pandemic due to COVID-19 was also taken into account.

\section{Materials and Methods}

The questionnaire method, quantitative and qualitative content-analysis were used as well as deductive and inductive approaches. The survey was conducted at the Ural State University of Economics (USUE) in Yekaterinburg. The participants were undergraduate students of the first and fourth years majoring in different fields (e. g. Information Technologies, Catering). It was assumed that students of the first and the last year could demonstrate some differences in their opinions, and this hypothesis was proved. In general, 30 undergraduate students took part in the survey (Similar study for Master students was undertaken at the same university earlier [10]).

A short questionnaire was introduced to undergraduate students. They had to choose options to answer multiple choice questions about different kinds of learning formats they had already experienced at the university. The first question concerned their preferred formats of study during the pandemic: a) traditional teaching, face-to-face format; b) distance learning (Portal of Electronic Resources of the USUE with different materials, classroom chat, separate message service) without virtual components (asynchronous learning); c) virtual classrooms (Teams); d) traditional blended learning (e. g. e-lectures + face-to-face seminars). Also for further qualitative analysis students were asked about their reasons for choosing an option. The second question referred to digital learning only. The students were asked if they preferred classical learning as an online edition (e-lectures and seminars via videoconferencing) or specially designed online courses including different resources (e-lectures, videos, interactive modules with tasks and tests based on digital platforms). The last option was not introduced at the university. Again, the students had to comment on their choices. 


\section{Results and Discussions}

For the first year students the following data were obtained: in the first question the majority of students (64\%) chose answer d) - "blended learning". Options a) - "traditional training on campus" and c) - "distant learning in virtual classrooms" were chosen by $18 \%$ of the respondents, respectively. Option b) - "distance learning without virtual classrooms" (using the provided electronic resources, where you can upload and download materials, chat and / or on the forum with teachers, send messages, etc.) was not chosen at all $(0 \%)$. Obviously, the lack of real-time communication when using this format is assessed negatively (Fig. 1).

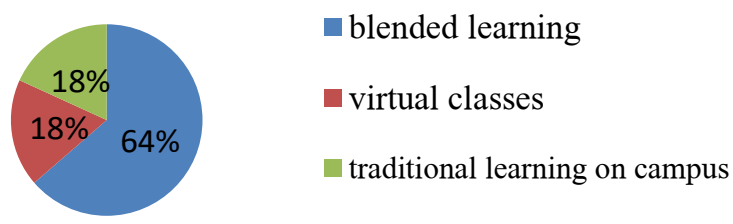

Fig. 1. The choice of learning formats by undergraduate students ( $1^{\text {st }}$ year $)$.

Based on the survey, we can conclude that option d) - "blended learning" is the most preferable. When explaining the reasons, students most often indicated the opportunity for immediate feedback, real-time communicating with classmates and teachers, better mastering the material, especially in some subjects (e.g. Higher Mathematics). It was noted that lectures are more convenient in online format, since they can be downloaded and watched at a convenient time and pace. Several students mentioned reducing the risk of infecting as an important factor during the pandemic.

Students who chose virtual classes gave one main reason - more free time. This shows that they evaluate distance learning as less time-consuming.

$2 \%$ of students who chose traditional education on-campus noted that it is easier/more convenient, and constant intensive workload is also important to them.

The second question revealed that $72 \%$ of students prefer option b) - "specially designed courses with integrated materials". The remaining $28 \%$ chose classic online education (the same lectures in video format and classes in virtual classrooms) (Fig. 2).

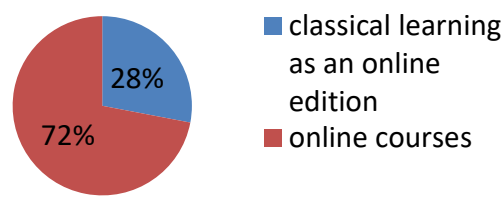

Fig. 2. Preferences for learning in digital landscape by undergraduate students ( $1^{\text {st }}$ year).

At the same time, explanations of the reasons showed that students have quite ambiguous idea of what specially designed courses with integrated materials are. At school and at their university they have not experienced such format yet. $36 \%$ of students did not explain the reason. The remaining $64 \%$ noted the following:

- the material with additional training tasks is better learnt and assimilated;

- recordings of lectures/classes can be viewed again and you can complete tasks at your own pace;

- it is more interesting to study this way, because you do not need to write anything down.

Students who chose option a) noted that in virtual classrooms in real time there are more opportunities for feedback. 
Below there are data obtained for the fourth year undergraduate students. The survey showed that no one chose option b) - "distance learning without virtual classes". $20 \%$ preferred option a) - "traditional education on campus". The remaining answers were equally divided between options c) and d) $-40 \%$ each (distance learning in virtual classrooms and blended learning) (Fig. 3).

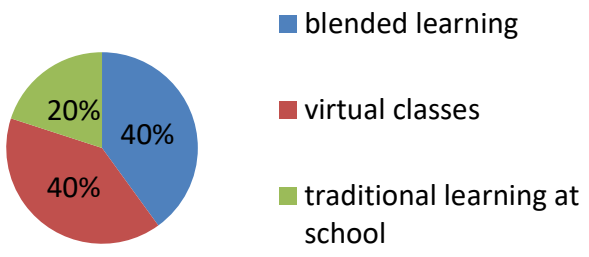

Fig. 3. The choice of learning formats by undergraduate students ( $4^{\text {th }}$ year).

Among the reasons explaining the choice of option a) such factor as fee appears - some students think that that recalculation is necessary because on-campus learning and distance learning differ, and they initially chose on-campus learning. Without recalculation they would prefer traditional on-campus learning. The convenience of traditional on-campus learning is also emphasized. Of course, these students do not take into account that the lower fee for distance course derives from a completely different study load, but their study load online was equal to the study load for on-campus students.

Students, having chosen the option of distance learning in virtual classrooms (c), note the danger during the pandemic as well as the convenience and time saving. For blended learning (d), the convenience of e-lectures and the advantages of face-to-face seminars, when personal communication is possible, were stated.

When answering the second question, most of the fourth-year students $(60 \%)$ chose option b) - "specially designed online courses with integrated materials". It was pointed out that this format provides more opportunities for better adoption of knowledge; it is more interesting; interactive; improves quality of education. It should be noted that, again, students understand this format ambiguously: it is considered, for example, as a way to simplify the perception of the material, as an opportunity to increase interaction between teachers and students, as a kind of complementation or supplement to virtual classes. Students who chose option a) - "distance learning in virtual classroom" make up 40\%. They note that such training is more familiar and convenient. Some students believe that special skills are required to successfully master the material in e-courses, and it may also take even longer than within familiar format (Fig. 4).

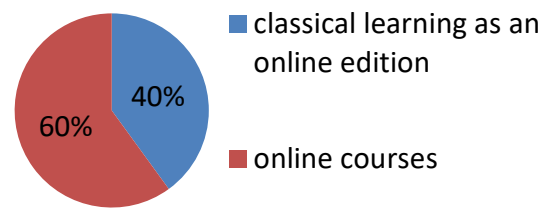

Fig. 4. Preferences for learning in digital landscape by undergraduate students ( $4^{\text {th }}$ year).

After comparing the results of the first and the fourth year students, the following factors were revealed:

1) None of the respondents chose option b) - "distance learning without virtual classrooms". It can be stated that learning without real time communication, in the opinion of the respondents, is practically impossible. Chat rooms and forums cannot replace fast and effective face-to-face or online real-time communication. 
2) If first-year students mainly choose the format d) - "blended learning" (64\%), then the preferences of senior students are divided between virtual classes and blended format in equal proportions ( $40 \%$ each). All of them note the convenience of listening to e-lectures and the effectiveness of face-to-face seminars. Also, risks during the pandemic and time saving are the reasons for this choice.

3 ) If among first-year students only $2 \%$ choose traditional education on campus, then among the fourth-year students the share is ten times higher $-20 \%$. Perhaps this is due to the fact that freshmen have already managed to experience the features of distance learning at school, since the pandemic started at the end of their last school year, and it was not so difficult for them to adapt to distance learning at the university. The 4th year students have never experienced such a format before and feel stressed, besides, they are in their graduation course. Half of the 4th year students who chose option a) - "traditional learning on campus", also raised the issue with the fee, since, in their opinion, they did not receive the level of education that they had before the introduction of the distance learning.

4) Among the 4th year students, the percentage of people who chose option b) in the second question ("learning on electronic platforms in online courses": $60 \%$ versus $72 \%$ for the first year students) turned out to be lower. In either case, students represent this learning format differently, pointing out that it is more interesting to study this way, the perception of the material is simplified and it is assimilated better. Senior students also note negative aspects - the need to get used to this format, time costs, difficulties for teachers. First year students do not reflect in this direction, they put the emphasis on simplifying the learning process (no notes, their own pace of learning).

The above results show that the digitalization of the learning process is perceived by different generations of students as a natural and necessary process in education. The younger generation of freshmen shows a greater interest in digitalization - fewer students choose traditional education on campus, most of the respondents are ready to get educated via e-courses on digital platforms. It is also worth noting that students do not have entirely clear ideas about this format of study. At least, the need to have a high level of selforganization is underestimated (there is no timetable for classes) as well as time costs, the actual lack of real-time communication. The last is, at the same time, seen as a problem, especially by freshmen (when choosing a blended learning format, most of the respondents noted the need for personal contact with classmates and teachers).

\section{Conclusion}

The analysis of data shows that different age groups of undergraduate students have different preferences; however, there are common points. Thus, the first-year students prefer blended learning, and the fourth-year students also choose this format, along with distance learning in virtual classes. From our point of view, this choice results from the fact that technologies cannot completely replace face-to-face format of education with its reallive exchanging information and experience. This format allows you to quickly transmit various meanings, get answers to questions immediately and, in general, contributes to the intensification of the information exchange process.

Of all the students, traditional education was chosen by the largest number of fourthyear students $(20 \%)$. Perhaps this is due to the need for face-to-face seminars and consultations in the graduation year. Distance learning without virtual component (asynchronous learning without any interactive online tasks) was not chosen. This learning option is obviously considered as the least effective.

It is remarkable that in the digital environment specially designed online courses with integrated materials were chosen by the majority of the first and fourth year students. The survey shows that not all of them have a clear idea of such training. This may be due to the 
lack of learning experience in this format. However, our research proves that students expect the development of online courses. Thus, based on the general trends and empirical data, it can be assumed that such courses will command a larger part in the curricula. At the same time, traditional education with face-to-face communication between teachers and students is still important to students.

The following quite complicated strategy can be considered as a reasonable one: the emphasis should be on the blended format - face-to-face learning experience on campus complemented by the distance component in the form of synchronous virtual classes, enriched by asynchronous online electronic courses with e-lectures and interactive tasks for students.

\section{References}

1. S. Fissi, A. Romolini, E. Gori, M. Contri, Journal of Cleaner Production, 279 (2021)

2. M. Schophuizen, M. Kalz, Int J Educ Technol High Educ, 17, 36 (2020)

3. I. S. Baranova, Trends in the development of electronic education in Russia and abroad. Materials of the I International Scientific Conference, 20 (Publishing House of the Ural State University of Economics, 2020)

4. R. Deng, P. Benckendorff, Int J Educ Technol High Educ, 18, 9 (2021)

5. W. G. Faix, J. Mergenthaler, The Creative Power of Education. On the Formation of a Creative Personality as the Fundamental Condition for Innovation and Entrepreneurial Success, 319 (Steinbeis-Edition, Stuttgart, 2015)

6. E. G. Efimova, Trends in the development of electronic education in Russia and abroad. Materials of the I International Scientific Conference, 52 (Publishing House of the Ural State University of Economics, 2020)

7. G. Heilporn, S. Lakhal, M. Bélisle, Int J Educ Technol High Educ, 18, 25 (2021)

8. M. Bower, J. Kenney, B. Dalgarno, M. J. W. Lee, G. E. Kennedy, 30th Annual conference on Australian Society for Computers in Learning in Tertiary Education, ASCILITE 2013, 92 (2013)

9. D. A. Sprenger, A. Schwaninger, Int J Educ Technol High Educ, 18, 8 (2021)

10. I. A. Stikhina, Advances in Economics, Business and Management Research, 156. Proceedings of the 2nd International Scientific and Practical Conference on Digital Economy (2020) 